Int. J. Dev. Biol. 62: 819-825 (2018)

https://doi.org/10.1387/ijdb.180238fb

\title{
The genetics and the molecular functions of the PREP1 homeodomain transcription factor
}

\author{
DIVYA PURUSHOTHAMAN and FRANCESCO BLASI* \\ IFOM (Foundation FIRC Institute of Molecular Oncology), Milano, Italy
}

\begin{abstract}
Prep1 (pKnox1) is a homeodomain transcription factor of the TALE superclass whose members can act as co-factors of Hox. Prep1 is essential for embryogenesis, but in the adult it also acts as a tumor suppressor. We describe and analyze here the available mutant mice, their phenotypes and a few discordant cases. Moreover we specify the basic rules underlying the binding of Prep1 and its TALE partners to DNA, and their plasticity during embryonic development. We finally review recent data on Prep1 which indicate a very basic cellular function at the level of DNA replication and DNA damage.
\end{abstract}

KEY WORDS: Prep1, pKnox1, tumor, tumor suppressor, epiblast

\section{Introduction}

Prep1 (PKnox1) is a homeodomain transcription factor and a cofactor of Hox proteins belonging to the TALE (Three Amino acids Loop Extension) super class of the Homeobox proteins (reviewed in (Moens and Selleri, 2006). The TALE superclass comprises two families: PBC (Pbx1-4) and Meinox. The Meinox family consists of two sub families; Meis (Meis1-3) and Prep (Prep1-2). All TALE proteins share a very similar homeodomain sequence characterized by the presence of a three amino acids loop extension. Additionally, the Meinox family contains a conserved domain through which they interact with the PBC domains of Pbx proteins. A range of studies have shown that co-operative binding with TALE super class proteins, greatly increases the DNA binding specificity of Hox factors (Mann and Affolter, 1998; Mann and Chan, 1996; Mann et al., 2009). Like in all homeobox proteins, DNA binding of Prep1 is brought about and strengthened by its hetero-dimerization with other homeodomain partners, members of the PBC family (Pbx1-4). In addition, Prep-Pbx can also form ternary complexes with HoxB1 and bind to sequences which are essential for the expression of several Hox genes in vitro and in vivo (Ferretti et al., 2005; Ferretti et al., 2000). Chipseq data in mouse embryos show that Prep1 and Pbx1 binding sites overlap with each other and also with some of the Hox binding sites, thus participating in the regulation of Hox gene expression (Penkov et al., 2013). A role for Prep1 in HoxB and HoxA gene expression has been shown in Zebrafish (Deflorian et al., 2004). However, more recent studies suggest that TALE proteins also have Hox independent functions
(Laurent et al., 2007; Moens and Selleri, 2006).

Biochemical and genetic properties of Prep1, as well as its role in cancer have been reviewed recently (Blasi et al., 2017; Longobardi et al., 2014). Here we will review the role of Prep1 in development and organogenesis as demonstrated by various mutants, mostly in mice. Further, we will also review the basic rules of TALE binding to DNA and their physiological significance. Finally, we will mention recent findings which reveal a basic cellular function for the Prep1 protein.

\section{Mutants and down-regulation phenotypes}

Multiple Prep1-deficient mutants have been isolated (table 1). Prep $1^{i / i}$ is a hypomorphic mutation, caused by an insertion of a beta-galactosidase gene containing a splice site at the 3 ' end that

\footnotetext{
Abbreviations used in this paper: BrdU, bromodeoxyuridine; ChIP-Seq, chromatin immunoprecipitation followed by DNA sequencing; Cre, cyclization recombinase of E. coli virus P1; DDR, DNA damage repair; DECA, decameric Prepl consensus sequence; DN, double negative thymocytes (for CD4 and CD8 surface markers); DP, double positive thymocytes (for CD4 and CD8 surface markers); ES, embryonic stem; FL, fetal liver; HEXA, hexameric Prepl consensus sequence; HSPC, hematopoietic stem progenitor cell; LAD, lamin associated domain; MEF mouse embryo fibroblast; Meis, myeloid ecotropic viral integration site ; OCTA octameric Prepl consensus sequence; pKnoxl, Pbx/Knotted 1 box homeobox; Pbx, Pre-B-cell leukemia homeobox; Prep1, Pbx-regulating protein-1; SP, single positive thymocytes (for CD4 or CD8 surface markers); TALE, three amino acids loop extension; WT, wild type.
} 
splices out the normal Prep1 mRNA (Ferretti et al., 2006). Since this splice site is not $100 \%$ efficient, Prep $1^{1 / i}$ embryos still produce a small amount of normal Prep1 mRNA and protein. The presence of residual Prep1 allows the embryo to survive until e17. Seventy five percent of the homozygous embryos from a heterozygous Prep $1^{+/ i}$ x Prep $1^{+/ i}$ cross die at about e17.5 while $25 \%$ are born and give rise to Prep $1^{i / i}$ mice that live an almost normal-length life (Ferretti et al., 2006). Instead in Prep1 null mice (Prep $1^{-/}$), exons 7 and 8 corresponding to the amino-terminal region of the homeodomain are deleted. No truncated protein was observed although the mRNA corresponding to the deleted gene was visible. No mice carrying the Prep 1\% mutation was born, and no embryo older than e7.5 (Fernandez-Diaz et al., 2010). A trans heterozygous mutant mice (Prep $1^{i /}$ ) was developed by crossing Prep $1^{1 / i}$ with Prep $1^{1 /+}$ mice and should have an intermediate Prep1 expression levels (not measured). The embryos survived till e12.5-14.5 (Rowan et al., 2010). A conditional Prep1 knockout mice was produced by Cre-mediated deletion of exon 8 (Carbe et al., 2012). Deletion of Prep1 using ubiquitously expressed Ella-Cre yielded no homozygous Prep $1^{-/-}$genotype at e12.5 (Carbe et al., 2012) agreeing with the observation that complete deletion of Prep1 is early embryonic lethal (Fernandez-Diaz etal., 2010). This mutation, however, generates a 59kDa truncated Prep1 band in whole embryo, though the effects, if any of this truncated form was not tested (Carbe et al., 2012). An additional Prep1 conditional deletion of exon 3 was also generated with no expression of truncated products (Yoshioka etal., 2015). These mice showed some defects in adult haematopoiesis.

As shown in Table 1 , studies in $D$. rerio and $X$. laevis also have given useful information. In zebrafish, the most evident phenotype of Prep1.1 morpholino down-regulation is the apoptosis in the nervous system, analogous to that in the mouse (see below). Moreover, the data also show an important role on the segmentation and patterning of the hindbrain with loss of several hindbrain markers, including the anteriorly expressed Hox genes. This affects the migration of facial nerve motor neurons and the lack of reticulospinal neurons. Finally, the head of the Prep1.1 morphants lacked completely all pharyngeal cartilages because of the inability of neural crest cells to differentiate into chondroblasts
(De Florian et al., 2004).

Also in $X$. laevis Prep1 is involved in development. A recent study on the effect of YAP down-regulation on retinal stem cell population has uncovered several key phenotypes reminiscent of Prep1 down-regulation like the reduced size or absence of the eye, changes in cell cycle status, changes in the temporal regulation of DNA replication and subsequent DNA damage and apoptosis (Cabochette et al., 2015). Interestingly, PREP1 is identified as an interacting partner of YAP in the cytoplasm of retinal stem cells. The interaction was also confirmed by immunoprecipitation of tagged proteins. Further, knockdown of PREP1 rescues the phenotype with significant reduction in eye size and lower numbers of cells in mid/late S phase. Finally, knockdown of Prep1 rescues the phenotypes observed in YAP over-expression suggesting a synergistic interaction between the two proteins. However, details of this interactions are still outstanding.

\section{Embryonic and fetal lethality}

The difference in timing of the embryonic lethality of Prep 1-/-null embryos (Fernandez-Diaz et al., 2010) v. the later death of the hypomorphic Prep $1^{i / i}$ embryos must reside in the $3-10 \%$ residual expression of the protein in the latter mice (Ferretti et al., 2006). Trans heterozygous Prep 1/ mutants which should have an intermediate expression level of (i.e. about $1-3 \%$ of control), on the other hand survive till e12.5 (Rowan et al., 2010). Therefore, the absence of Prep1 leads to death at the epiblast stage; its expression at one twentieth of the normal Prep1 level (Prep $\left.{ }^{i /}\right)$ allows to prolong the embryonic life span from e7.5 to e12.5; expression at one tenth of the normal level (Prep $\left.1^{i h}\right)$ prolongs life for ten more days almost until the end of gestation. Further, Prep $1^{+/}$embryos develop normally (Fernandez-Diaz et al., 2010) indicating that half the normal expression of Prep1 is enough to ensure normal embryonic development. These data show that during embryogenesis, minor difference in Prep1 levels can profoundly affect development. Why $25 \%$ of the Prep $1^{i / i}$ embryos are born and live normal length life is unknown (Ferretti et al., 2006) but it is possible that a slightly higher Prep1 expression makes the difference.

TABLE 1

\section{PHENOTYPES OF DIFFERENT MUTANTS IN THE PREP1 (PKNOX1) GENE}

\begin{tabular}{|c|c|c|}
\hline Genotype & Time of embryonic death & Phenotype \\
\hline Mouse: Prep1 $1^{i i}$ & e17.5 & $\begin{array}{l}\text { Angiogenesis, erythropoiesis, oculogensis (Ferretti, et.al., 2006) } \\
\text { T-cell development in adult (Penkov et.al., 2005) } \\
\text { B-cell development in the embryo (Di Rosa P et.al., 2007) } \\
\text { Extended Apoptosis (Micali et.al., 2009) } \\
\text { Tumorigenesis (Longobardi et.al., 2010) } \\
\text { Chromosome aberrations (lotti et.al., 2011) } \\
\text { Hematopoietic stem cell cycling (Modica et.al., 2014) }\end{array}$ \\
\hline $\begin{array}{l}\text { Mouse: Prep } 1^{-1} \\
\text { Deletion of exon } 7 \text { and } 8\end{array}$ & E6.5 & $\begin{array}{l}\text { Embryos fail to gastrulate. Epiblasts cells undergo p53 dependent apoptosis (Fernandez-Diaz et.al., 2010). The same pheno- } \\
\text { type is visible also in heterozygotes in the Atm }{ }^{-1} \text { background. }\end{array}$ \\
\hline Mouse: Prep1/- & $\mathrm{E} 12.5-14.5$ & Eye development (Rowan et.al., 2010) \\
\hline $\begin{array}{l}\text { Mouse:Prep } 1^{D / D} \\
\left.\text { (Ella-Cre Prep1 } 1^{\text {th }}\right)\end{array}$ & $<\mathrm{e} 12.5$ & Apa2-Cre;Prep $1^{\text {tff }}$ and Le-Cre;Prep $1 f^{f t}$ : Healthy and fertile mice. No eye phenotype (Carbe et.al., 2012) \\
\hline $\begin{array}{l}\text { Mouse: Prep } 1^{\text {DSM }} \\
\text { (Prep } 1^{\text {ti Crel+ }) \text { Muscle specific conditional }}\end{array}$ & viable & Increased mitochondrial enzymatic activity and better endurance; higher maximal oxidative capacity (Kanzleiter et.al., 2014) \\
\hline $\begin{array}{l}\text { Mouse: Prep1 CKO } \\
\text { Conditional deletion of exon } 3\end{array}$ & viable & $\begin{array}{l}\text { Tie-2 Cre;Prep1ff: defects in thymocyte development, Increased HSPC cycling (Yoshioka et.al., 2015). } \\
\text { Rosa26-CreER }{ }^{\top 2} ; \text { PKnox } 1^{\prime f / 4} \text { and TNAP-Cre; PKnox1ff: Defective spermatogenesis (Kawai et.al., 2018) }\end{array}$ \\
\hline $\begin{array}{l}\text { D. rerio: } \\
\text { Morpholino down-regulation of Prep1.1 }\end{array}$ & Late embryonic lethal & $\begin{array}{l}\text { Extended apoptosis mostly located in embryonic neural tissues. Defects in hindbrain segmentation, patterning and cranial } \\
\text { nerves formation, loss of expression of anterior Hox genes in hindbrain; loss of pharyngeal cartilages due to defective chon- } \\
\text { droblast differentiation (Deflorian et.al., 2004) }\end{array}$ \\
\hline $\begin{array}{l}\text { X. laevis: } \\
\text { Morpholino down-regulation of Prep1 }\end{array}$ & Retinal stem cells & Reduced size of (or absent) eye, DNA damage and apoptosis (Cabochette et al., 2015). \\
\hline
\end{tabular}




\section{Interpreting phenotypes}

Within the TALE family, each sub-family, Pbx, Meis and Prep, has an identical DNA binding domain. Therefore, all proteins belonging to one group can bind the same target sequence. Hence, the interpretation of the KO mice phenotype is in fact complicated when isoforms or other TALE family members are expressed, which is the rule rather than the exception. Under these circumstances, the phenotype of the different Prep1 KO mice may also be interfered by the expression of Prep2 (pKnox2) (Fognani et al., 2002; Imoto et al., 2001). It should be noted, however, that the expression of this gene is different from Prep1; since however its homeodomain is identical (Haller et al., 2004; Haller et al., 2002) it might well, when expressed, bind the same Prep1 targets. Moreover, the existence of several alternative splicing forms (Haller et al., 2004) suggests a multiplicity of functions. Therefore, substitution of Prep1 with Prep2 might differentially affect different aspects of the Prep1 phenotypes. All these speculations need to be verified.

$\mathrm{Pbx} 1$ and Pbx2 can bind mostly the same genes (Penkov et al., 2013). Indeed, the genes bound by Pbx2 in the thymus where $\mathrm{Pbx} 1$ is largely absent, are found among the $\mathrm{Pbx} 1$ genes bound in the mouse embryo. In situations where multiple Pbx proteins are expressed, it is possible that the sites bound by different $\mathrm{Pbx}$ proteins are dictated by the relative concentration of the individual proteins. These data explain why $\mathrm{Pbx} 1$ and $\mathrm{Pbx} 2$ can at least partially complement each other (Capellini et al., 2006; Selleri et al., 2004). Further, Prep1 and Meis1 proteins display competitive binding to Pbx proteins in vivo (Dardaei et al., 2014), affecting the stability of the individual proteins (Ferretti et al., 2006; Laurent et al., 2015), raising the possibility of increased Meis-Pbx complexes in Prep1 knockouts. The observed phenotypes, therefore, should be re-examined on the basis of these considerations, to test whether they are due to the absence of the deleted-gene product or also due to the occupation of the same sites by other partially complementing transcription factors.

This type of considerations also raises other interesting questions. For example, if Prep1 acted uniquely through a dimer with Pbx1, one would expect that the Prep1 and Pbx1 KO embryos should die at a very similar embryonic age. However, the single Pbx1 KO embryos die much later than the Prep1 KO while the double Pbx1-Pbx2 KO embryos die earlier than $P b x 1 \mathrm{KO}$. Should one delete all three, or even four, Pbx genes to observe a Prep1like phenotype, i.e. death at the epiblast stage? A deeper analysis would clarify these issues and uncover mistaken interpretations.

\section{Organ specific differentiation-related phenotypes}

\section{Hematopoiesis}

Data on hematopoiesis from Prep $1^{\text {if }}$ mice (germline mutation) and Prep1CKO (somatic conditional) suggests that the intrinsic effect of Prep1 on hematopoiesis is controversial and possibly minimal. Prep $1 / i$ mice show reduced numbers of erythropoietic cells (Ferretti et al., 2006) and common myeloid progenitors (Di Rosa et al., 2007) in the embryo. Further, a block in B-cell differentiation in both embryo (Di Rosa et al., 2007) and adult (lotti et al., 2012) was reported in Prep 1/i mice and tamoxifen-inducible Rosa26-CreERmediated Prep1 knockout mice respectively. However, a Tie-2-Cre mediated hematopoietic and endothelial cell specific deletion of Prep1(Prep1CKO), did not display any defect in the maintenance or differentiation of hematopoietic cells in fetal livers nor any difference in early B-cell lineage or immature and mature B-cells (Yoshioka et al., 2015). Similarly, fetal livers from Prep $1^{i / i}$ mice revealed the

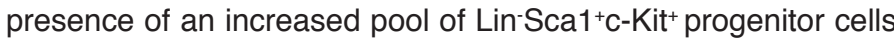
at the expense of highly replicative stem cell pool which exhaust rapidly their replicative potential (Modica et al., 2014). However, FL from Prep1CKO mice did not have a significantly higher pool of Lin-Sca ${ }^{+} \mathrm{C}-\mathrm{Kit}^{+}$cells (Yoshioka et al., 2015) indicating that the relative expression of other TALE proteins or differences due to germline vs somatic expression level can drastically modify the phenotype. Possibly the defects observed in Prep $1^{i / i}$ embryos could depend on fetal liver cells different from those originating from the tie-2-Cre lineage that provide niche function for the HSC. Another possible explanation for the discrepancy between the two reports might be the level of Prep1 interactors, ie Pbx and Meis proteins. While the expression of Pbx and Meis in Tie-2 Cre Prep1 CKO is not known, Prep $1^{i / i}$ mice and Prep 1/- ES cells show generally reduced levels of $\mathrm{Pbx}$ and Meis protein expression (Ferretti et al., 2006; Laurent et al., 2015). Since Pbx1 and Meis1 have been shown to be important in hematopoiesis (Azcoitia et al., 2005; DiMartino et al., 2001), it is conceivable that hematopoietic defects observed in Prep ${ }^{\text {i/i }}$ mice could be a compound effect of these interactors.

Nevertheless, Prep1 seems to have significant effect during T-cell development in thymus. In the adult Prep $1^{i / i}$ mice, even though a higher numbers of DN (double negative) thymocytes were present, due to increased apoptosis at the positive selection checkpoint of double positive (DP) thymocytes in the thymus, significantly lower SP (single positive) thymocytes were detected (Penkov et al., 2005). Consequently, an absolute decrease in the numbers of $\mathrm{CD}^{+}$and $\mathrm{CD}^{+}$peripheral T-cells in spleen, blood and lymphnodes was seen in Prep $1^{i / i}$ mice. Similar results were also obtained in a transgenic mice with a thymus specific expression of the $\mathrm{N}$-terminal fragment of $\mathrm{Pbx} 1$ which causes cytosolic sequestration of Prep1, which makes it unable to carry out its transcriptional activities (Penkov et al., 2008). Again, this induced a concomitant decrease of $\mathrm{Pbx} 2$ in these mice, suggesting that Prep1 acts in combination with its binding partners. Data from Prep1CKO also reports a significant decrease in single positive (SP) thymocyte even though the reduced thymic output did not result in reduced peripheral T-cell numbers as reported for Prep $1 / i$ mice (Yoshioka et al., 2015). Differences in the deletion strategy (germline vs somatic), differences in the mice background and/or differences in the levels of $\mathrm{Pbx}$ and/or Meis proteins could explain the changes in homeostatic expansion of peripheral T-cells.

\section{Oculogenesis}

Prep1 also regulates eye development. Reduction in the lens size, neural retina abnormalities and encasement of eyes deep within the head were observed with varying penetrance in Prep $1^{\text {in }}$ mice (Ferretti et al., 2006). The study also showed that the level of Pax 6, an essential factor for oculogenesis was reduced drastically in the iris, ciliar body, corneal epithelium and lens epithelium. Further, in WT mice, Prep1 co-localized with Pax 6 in these tissues. Using trans-heterozygotes Prep $1^{-/ i}$ mice with a further reduction in Prep1 protein levels, Rowan et.al., demonstrated a more severe phenotype with complete absence of the lens. In these mice lens epithelial cells, lens fiber cells or lens precursor cells were not formed. Prep 1/- mice also did not initiate Foxe3 expression (Rowan et al., 2010). However, direct involvement of Prep1 in the regulation 
of Pax 6 is difficult to ascertain, given that Meis 1 has been shown to regulate Pax 6 levels during vertebrate lens morphogenesis (Zhang et al., 2002). Though no data is available for mouse, Pbx proteins have been shown to regulate eye development in zebrafish, Xenopus and planaria (Chen et al., 2013; French et al., 2007; Morgan et al., 2004). Reduction in Pax 6 levels in the absence of Prep1 thus could be due to the concomitant decrease in $\mathrm{Pbx}$ and Meis proteins (Ferretti et al., 2006). This is the more likely scenario given that a more recent study using conditional knockout mice made by cre-mediated deletion of exon 8 of Prep1 gene failed to reproduce the eye phenotype. Both Ap2a-Cre- (expressed in the presumptive lens ectoderm at E8) and Le-Cre- (expressed in the lens and pancreas at E9.5) -driven knockout of Prep1 during lens development failed to show any lens defects in mutant mice and Pax6 was expressed at normal levels (Carbe et al., 2012). However, the levels of other TALE proteins in these mice was not measured. Further, the study also raises the possibility that lens extrinsic factors contribute to the phenotype since previous studies used germline mutants. However, another source of variability may be the presence of truncated Prep1 protein which lack the homeodomain in the conditional mutant (Carbe et al., 2012). A functional homeodomain-less splice form of Meis1 and its orthologue Homothorax is present in mouse and Drosophila (Noro et al., 2006). Truncated forms of Meis have also been identified in human colorectal cancer tissues (Crist et al., 2011). Therefore, it is necessary to rule out the possibility of a partially functional truncated Prep1 in order to understand the role of Prep1 in oculogenesis.

\section{Adipogenesis}

Prep1 appears to have a regulatory role in adipogenesis as well (Maroni et al., 2017). Both Prep $1^{1 / i}$ mesenchymal stromal cells from bone marrow and the 3T3L1 cell line down-regulated for Prep1 by an shRNA, reveal a pre-adipocytic stage in the absence of specific hormonal stimuli and a faster and more efficient adipogenesis after specific stimulation. Upon Prep1 down-regulation some of the key adipogenic factors are affected in the same direction as if they had been treated with the hormonal inducing cocktail: PPAR $\gamma$, CCAAT enhancer binding protein $\alpha(\operatorname{cEBP} \alpha)$ among others, are induced while Klf5, Pref1 and cEBP $\delta$ are repressed. Moreover, phosphorylation of Irs 1 and pAkt is greatly and rapidly increased by Prep1 down-regulation in the absence of the hormonal cocktail. The most important effect is the expansion of the DNA-binding landscape of $\mathrm{c} / \mathrm{EBP} \beta$ with a major pre-differentiation increase in DNA binding sites, which occurs without a concurrent increase or activation of the protein (Maroni et al., 2017). Therefore, possibly in 3T3L1 cells and in mesenchymal stromal cells Prep1 acts by repressing adipogenesis and its absence may modify the state of the genome making it more amenable to the induction of adipogenesis. While the mechanism is still not known, one attractive possibility is that Prep1 regulates adipogenesis by modifying the genomic accessibility by chromatin modifications.

\section{Spermatogenesis}

In mouse the highest expression of Prep1 mRNA is observed in the testes (Ferretti et al., 1999). The role of Prep1 in regulating spermatogenesis has been addressed recently in a Prep1 conditional knockout (Kawai et al., 2018). Prep1 expression is temporally regulated; first detectable at p6, increases with age and reaches a plateau with the first wave of spermatogenesis at p35. Both Rosa26 Cre-ERT2; Prep1 $1^{\text {fl/fl }}$ and germ cell specific TNAP-Cre; Prep1 $1^{\mathrm{flffl}}$ mice showed smaller testes with atrophic seminiferous tubules containing very few spermatocytes and accumulation of TUNEL ${ }^{+}$apoptotic cells (Kawai et al., 2018). In the absence of Prep1, spermatogenesis failed to proceed beyond the c-Kit ${ }^{+}$spermatogonial differentiation stage and subsequent stages including meiosis were absent. Absence of PCNA in Prep1-CKO c-Kit ${ }^{+}$spermatogonial cells suggests that defects in DNA replication could explain the arrest of spermatogenesis (Kawai et al., 2018).

\section{Cell-level phenotypes}

Prep1 and oxidative phosphorylation: Analysis of skeletal musclespecific Prep1 knockout revealed a significant increase in respiratory chain subunits like the succinate dehydrogenase subunit (Sdha) from complex 2, cytochrome c1 subunit (Cyc1) from complex 3, and ATP synthase subunit (Atp5k) from complex 5, at both mRNA and protein levels (Kanzleiter et al., 2014). Though increased mitochondrial DNA and increased activity of mitochondrial enzyme citrate synthase was detected in the muscle cells of Prep1-ablated mice, the mitochondrial volume fraction or ultra-structure was unchanged. Prep1 could be acting directly by stabilizing Mybbp1a (Diaz etal., 2007), as previously shown in Prep $1^{1 / i}$ muscles (Oriente et al., 2008), that in turn can repress PGC1- $\alpha$, a well-known regulator of muscle oxidative capacity. Additionally, Prep1 can also act directly through its binding at promoter regions of 16 mitochondrial proteins (Kanzleiter et al., 2014). Though Prep1 ablated skeletal muscles show increased PGC1- $\alpha$ which can drive mitochondrial biogenesis, surprisingly no change in mitochondrial volume fraction was observed in these cells.

Prep1, cell proliferation and DNA damage:An important phenotype of the loss of the Prep1 gene across different species is apoptosis. In zebrafish, acridine orange staining revealed widespread cell death in prep1.1 morphants. This effect was specific for prep1.1 since neither control nor $p b x 4$ (equivalent to $p b x 1$ in zebrafish) morphants showed any apoptosis. Likewise, TUNEL staining showed intense DNA fragmentation in the brain of prep1.1 morphants at the 22 somites stages, in particular in the hindbrain (De Florian et al., 2004). A similar effect has been observed also in the Prep $1^{i / i}$ mice. Sections of E9.5 and E11.5 Prep1/ii mice were positive in TUNEL analysis in the nervous system, the apoptosis being evident mostly in the nervous system, particularly in the hindbrain and in several intersomitic regions. The trend towards apoptosis was confirmed by biochemical studies on hypomorphic MEFs that identified genotoxic stress as a major cause of apoptosis in Prep $1^{i / i}$ MEFs (Micali et al., 2009). The tendency to apoptosis suggests the presence of DNA damage, which is an important clue to understand another function of Prep1, that of tumor suppression, since DNA damage is a major cause of cancer. Furthermore, Prep 1/ mice epiblasts undergo p53 dependent apoptosis (Fernandez-Diaz et al., 2010). This is exacerbated in the absence of Atm kinase which is essential for DNA repair, suggesting that the DNA damage accumulation is the trigger for apoptosis. Accumulation of DNA damage and errors in DNA damage repair machinery is the major cause of cancer (Khanna and Jackson, 2001). Indeed, Prep $1^{\mathrm{i} / i}$ mice which escape embryonic lethality and survive to adulthood develop tumors of various origins indicating that Prep1 is a tumor suppressor gene. Furthermore, this role of Prep1 is supported by the absence of Prep1 in a large percent of human cancers (Longobardi et al., 2010). Further experiments in Prep $1^{i / i}$ MEFs revealed gross chromosomal 
anomalies and high level of DNA damage, whereas the DNA Damage Response (DDR) machinery appeared to be functional. This was observed also in human Prep1 down-regulated fibroblasts (lotti et al., 2011). The presence of an intact DDR machinery suggest that the DNA damage accumulation in Prep1-deficient cells could be due to anomalies in DNA replication.

A recent study has analyzed DNA replication in Prep1 down regulated Hela cells and shows that in the absence of Prep1, the time spent by the cells in the early $S$ phase is decreased while that in the late $S$ phase is increased. This change is accompanied by an increase in the number of unscheduled origin firings (Palmigiano et al., 2018). Sequencing of BrdU-incorporated DNA by Repliseq revealed that $25 \%$ of the DNA was replicated earlier in Prep1-down regulated than in control cells. In fact, PREP1 down-regulation did not affect the replication timing of the entire DNA, but only of a fraction of the genome with very special properties. In the nucleus, the timing of replication is regulated by the attachment of $40 \%$ of the DNA to the nuclear lamina. These so called Lamin-Associated Domains (LAD) (Guelen et al., 2008) depend on a complex interaction of DNA with Lamins, major components of the nuclear lamina. The DNA bound to LADs is gene-poor, late-replicated and mostly silent (Guelen et al., 2008). In PREP1 down-regulated Hela cells about one quarter of the genome, mostly represented by the LADs and including most of the late-replicating genome, is replicated earlier in the $\mathrm{S}$ phase (Palmigiano et al., 2018). While the mechanism is not yet established, the data exclude the possibility that the shifted replication is related to the direct binding of PREP1 to DNA. Fig. 1 shows a proposed model for the effect of Prep1 on DNA replication. Since the data show a corresponding decrease of the Lamin B1 protein, it is possible that the effect of Prep1 is funneled via the control of the level of the Lamin proteins.

\section{DNAtarget sequence and Prep1 developmental functions}

ChIP-seq analysis of the mixed cell populations E10.5 embryo trunk has identified three specific consensus DNA-binding sites for TALE transcription factors, DECA, OCTA and HEXA, corresponding to previously observed targets of TALE proteins. The DECA sequence TGANTGACAG, previously known as a Prep1 and a Pbx1 half-site combination (Knoepfler et al., 1997), is indeed bound in vivo by both Prep1 and Pbx1, hence likely by the Prep-Pbx dimers and includes the highest affinity sites. In a large number of these sites, DECA is followed 7-10 nucleotides downstream by the CCAAT sequence, known to bind NF-Y (Penkov et al., 2013).

Meis1, on the other hand, preferentially binds to the TGATTTAT (OCTA) type sequence, corresponding to the Hox-Pbx DNA-binding site (Penkov et al., 2013). Also these peaks are likely bound by the Pbx1-Meis1 dimers. Finally, Prep1, Pbx1 and Meis1 also bind the HEXA motif TGACAG, although Prep1 less frequently than the others (Penkov et al., 2013).

In this and many other ChIP-seq studies, Prep1 binds more frequently promoters than enhancers, while Meis 1 does the reverse (Blasi et al., 2017). Gene Ontology analysis of the binding sites in the E10.5 embryo shows that the genes bound by Meis 1 are highly enriched in the embryonic development categories whereas those bound by Prep1 are enriched in genes more related to basic cell functions (Penkov et al., 2013). However, it is clear that Prep1 sites differ from cell to cell with only a conserved core set of genes (Blasi et al., 2017; Laurent et al., 2015; Dardaei et al.,
2015; Palmigiano et al., 2018). Finally, the binding specificity is also affected by the concentration of the proteins in vivo. Indeed, when the intracellular concentration of Prep1 is artificially increased, the number of bound genes increases proportionally and new binding variant consensus sequences. In this case Prep1 tends to bind much more to enhancers than promoters, indicating a change in the transcription regulation mechanisms (Dardaei et al., 2015).

In mouse ES cells, that share the same binding rules with all other cells, Prep1 target genes are more enriched in embryonic development genes. In particular the developmentally important signaling pathways like Wnt, Fgfand Hhare among Prep1 binding sites (Laurent et al., 2015).

In addition to the essential functions at post-gastrulation and adult stages, TALE proteins clearly are also essential before gastrulation. The most important example is the phenotype of Prep1 null embryos that die before gastrulation. At this stage, Prep1 and Pbx are present as maternal transcripts (Fernandez et al., 2010) which will become ubiquitously expressed in later embryos. An essential Pbx function at this stage has not been directly demonstrated but is likely to be obscured by complementation of other family members. Indeed, at early stages Prep1 and Pbx are bound at regulatory elements even before the expression of cooperating transcription factors factors (Berkes et al., 2004).

An important report by Sagerstrøm group while confirming in zebrafish embryos all of the above DNA-binding rules for TALE factors, shows that the DNA-binding of maternal v. somatic TALE factors is somewhat different and has important functional implications. In fact, the pre-gastrulation stage separates the DNA-binding landscapes of maternal v. somatic TALE factors. At blastula maternal Prep1 and Pbx1 bind the combined DECA...CCAAT sequence at promoter sites, adjacent to sites occupied by NF-Y pioneer factors; this binding is required for the transition into active chromatin of

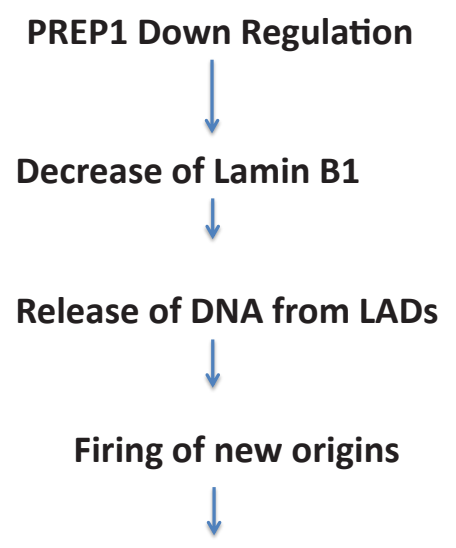

\section{Late to Early shift in LADs replication}

Fig. 1. Possible mechanism explaining the effect of PREP1 downregulation on DNA replication timing in HeLa cells. Down-regulation of PREP1 in HeLa has profound effects (Palmigiano et al., 2018), among which a decrease in Lamin B1, a major component of the nuclear lamina. In the fraction of DNA (about 40\%) associated with Lamins and forming the Lamin Associated Domains (LADs), DNA replication occurs late in the $S$ phase and most genes are silenced. It is likely that the decrease of Lamins caused by PREP1 down-regulation, induces a release of DNA which therefore becomes free to be replicated ahead of time through the firing of new origins. 
a gene network that controls anterior embryonic development. At later stages, the binding landscape of these factors expands to include the OCTA and HEXA sites, mostly present in enhancers also associated with the same network. These changes appear to be associated to modifications of chromatin accessibility (Ladam et al., 2018).

\section{Is Prep1 a developmental gene?}

While hypomorphic Prep $1^{\text {if }}$ or conditional knockouts show significant defects in embryonic development some of which have been reviewed here, a germline knockout of Prep1 dies before gastrulation (Fernandez-Diaz et al., 2010). The pre-gastrulation death does not appear to be due to the loss of a developmental function. In fact, at the epiblast stage, the expression of Oct4 and Nanog, essential for the multi-potency of the epiblast, is not affected in Prep 1\%embryos which express no Prep1 mRNA, and the cells die because they undergo Tp53-dependent and Atm-exacerbated apoptosis. In this case, epiblast cells die because they accumulate DNA damage and undergo apoptosis, and the absence of these cells blocks development.

On the other hand, Prep 1\%ES cells, although able to propagate themselves in culture, undergo apoptosis in response to differentiation cues (Fernandez-Diaz et al., 2010). This phenotype may be due to developmental defects since Prep $1^{\%}$ ES show an altered timing of expression of developmentally fundamental genes which can be partially rescued by reintroduction of Prep1 (Laurent et al., 2015). Hopwever, a mechanism similar to that described by Palmigiano et al., (2018), i.e accumulation of DNA damage, may also be responsible for this phenotype. Other developmental phenotypes observed in various tissues of Prep1 mutant mice are accompanied by defects in cell cycle status and proliferation; hematopoietic stem/progenitor cells (Modica et al., 2014; Yoshioka et al., 2015), thymocytes (Penkov et al., 2005; Penkov et al., 2008) and spermatogonial cells (Kawai et al., 2018). Both in mouse and zebrafish (Ladam etal., 2018) embryos the pre- and a post-gastrulation Prep1 phenotypes may depend on different mechanisms. Should the DNA binding properties of TALE proteins in zebrafish be recapitulated in the mouse, the molecular mechanisms and biological properties of Prep1 in a pre- v. post-gastrulation stages would be coordinated with its differential DNA-binding mode. This hypothesis, suggested by the differential DNA-binding distribution in zebrafish (Ladam et al., 2018) requires, and is worth of, further investigation.

Because paralogs of the TALE proteins might substitute for a missing one, their gene expression must also be considered in the interpretation of the KO phenotypes. Prep1 is expressed ubiquitously in an e8.5 developing embryo as opposed to the Prep2, Meis 1 and Meis2 genes which have a more restricted expression pattern (Fernandez-Diaz et al., 2010). The combined expression of all Pbx genes, instead, recapitulates that of Prep1.

\section{Conclusions}

A review of the phenotypic analysis of mice mutants suggests that Prep1 regulates basic cellular functions like DNA replication and DNA damage thereby regulating biological functions like embryonic development and tissue homeostasis in the adult. However, it is also clear that Prep1 has been generally under-investigated and that a myriad of other effects and mechanisms await to be uncovered. The precise scope and nature of the Prep1-Tp53 axis, the exact molecular mechanism of DNA damage accumulation in Prep1 down-regulated cells etc need to be investigated thoroughly. It must be noted that the number of labs working on Prep1 is very small. We hope that more labs will become interested to join this field of research in the near future.

\section{References}

AZCOITIA, V., ARACIL, M., MARTINEZ, A.C. and TORRES, M. (2005). The homeodomain protein Meis1 is essential for definitive hematopoiesis and vascular patterning in the mouse embryo. Dev Biol 280: 307-320.

BERKES CA, BERGSTROM DA, PENN BH, SEAVER KJ, KNOEPFLER PS, TAPSCOTT SJ. (2004). Pbx marks genes for activation by MyoD indicating a role for a homeodomain protein in establishing myogenic potential. Mol Cell. 14:465-77

BLASI, F., BRUCKMANN, C., PENKOV, D. and DARDAEI, L. (2017). A tale of TALE, PREP1, PBX1 and MEIS1: Interconnections and competition in cancer. Bioessays 39

CABOCHETTE, P., VEGA-LOPEZ, G., BITARD, J., PARAIN, K., CHEMOUNY, R., MASSON, C., BORDAY, C., HEDDERICH, M., HENNINGFELD, K.A., LOCKER, M., et $A L$. , (2015). YAP controls retinal stem cell DNA replication timing and genomic stability. Elife 4: e08488.

CAPELLINI, T.D., DI GIACOMO, G., SALSI, V., BRENDOLAN, A., FERRETTI, E., SRIVASTAVA, D., ZAPPAVIGNA, V. and SELLERI, L. (2006). Pbx1/Pbx2 requirement for distal limb patterning is mediated by the hierarchical control of Hox gene spatial distribution and Shh expression. Development 133: 2263-2273.

CARBE, C., HERTZLER-SCHAEFER, K. and ZHANG, X. (2012). The functional role of the Meis/Prep-binding elements in Pax6 locus during pancreas and eye development. Dev Biol 363: 320-329.

CHEN, C.C., WANG, I.E. and REDDIEN, P.W. (2013). pbx is required for pole and eye regeneration in planarians. Development 140: 719-729.

CRIST, R.C., ROTH, J.J., WALDMAN, S.A. and BUCHBERG, A.M. (2011). A conserved tissue-specific homeodomain-less isoform of MEIS1 is downregulated in colorectal cancer. PLoS One 6: e23665.

DARDAEI, L., LONGOBARDI, E. and BLASI, F. (2014). Prep1 and Meis1 competition for $\mathrm{Pbx} 1$ binding regulates protein stability and tumorigenesis. Proc Natl Acad Sci USA 111: E896-905

DEFLORIAN, G., TISO, N., FERRETTI, E., MEYER, D., BLASI, F., BORTOLUSSI, M. and ARGENTON, F. (2004). Prep1.1 has essential genetic functions in hindbrain development and cranial neural crest cell differentiation. Development 131:613-627.

DI ROSA, P., VILLAESCUSA, J.C., LONGOBARDI, E., IOTTI, G., FERRETTI, E., DIAZ, V.M., MICCIO, A., FERRARI, G. and BLASI, F. (2007). The homeodomain transcription factor Prep1 (pKnox1) is required for hematopoietic stem and progenitor cell activity. Dev Biol 311: 324-334.

DIAZ, V.M., MORI, S., LONGOBARDI, E., MENENDEZ, G., FERRAI, C., KEOUGH, R.A., BACHI, A. and BLASI, F. (2007). p160 Myb-binding protein interacts with Prep1 and inhibits its transcriptional activity. Mol Cell Biol 27: 7981-7990.

DIMARTINO, J.F., SELLERI, L., TRAVER, D., FIRPO, M.T., RHEE, J., WARNKE, R., O'GORMAN, S., WEISSMAN, I.L. and CLEARY, M.L. (2001). The Hox cofactor and proto-oncogene $\mathrm{Pbx} 1$ is required for maintenance of definitive hematopoiesis in the fetal liver. Blood 98: 618-626.

FERNANDEZ-DIAZ, L.C., LAURENT, A., GIRASOLI, S., TURCO, M., LONGOBARDI, E., IOTTI, G., JENKINS, N.A., FIORENZA, M.T., COPELAND, N.G. and BLASI, F. (2010). The absence of Prep1 causes p53-dependent apoptosis of mouse pluripotent epiblast cells. Development 137: 3393-3403.

FERRETTI, E., CAMBRONERO, F., TUMPEL, S., LONGOBARDI, E., WIEDEMANN, L.M., BLASI, F. and KRUMLAUF, R. (2005). Hoxb1 enhancer and control of rhombomere 4 expression: complex interplay between PREP1-PBX1-HOXB1 binding sites. Mol Cell Biol 25: 8541-8552.

FERRETTI, E., MARSHALL, H., POPPERL, H., MACONOCHIE, M., KRUMLAUF, R and BLASI, F. (2000). Segmental expression of Hoxb2 in r4 requires two separate sites that integrate cooperative interactions between Prep1, Pbx and Hox proteins. Development 127: 155-166.

FERRETTI, E., SCHULZ, H., TALARICO, D., BLASI, F. and BERTHELSEN, J. (1999). The PBX-regulating protein PREP1 is present in different PBX-complexed forms 
in mouse. Mech Dev 83: 53-64.

FERRETTI, E., VILLAESCUSA, J.C., DI ROSA, P., FERNANDEZ-DIAZ, L.C., LONGOBARDI, E., MAZZIERI, R., MICCIO, A., MICALI, N., SELLERI, L., FERRARI, G., et $A$ L., (2006). Hypomorphic mutation of the TALE gene Prep1 (pKnox1) causes a major reduction of $\mathrm{Pbx}$ and Meis proteins and a pleiotropic embryonic phenotype. Mol Cell Biol 26: 5650-5662.

FOGNANI, C., KILSTRUP-NIELSEN, C., BERTHELSEN, J., FERRETTI, E., ZAPPAVIGNA, V. and BLASI, F. (2002). Characterization of PREP2, a paralog of PREP1, which defines a novel sub-family of the MEINOX TALE homeodomain transcription factors. Nucleic Acids Res 30: 2043-2051.

FRENCH, C.R., ERICKSON, T., CALLANDER, D., BERRY, K.M., KOSS, R., HAGEY, D.W., STOUT, J., WUENNENBERG-STAPLETON, K., NGAI, J., MOENS, C.B., et $A L$., (2007). Pbx homeodomain proteins pattern both the zebrafish retina and tectum. BMC Dev Biol 7: 85.

GUELEN, L., PAGIE, L., BRASSET, E., MEULEMAN, W., FAZA, M.B., TALHOUT, W., EUSSEN, B.H., DE KLEIN, A., WESSELS, L., DE LAAT, W., et AL., (2008), Domain organization of human chromosomes revealed by mapping of nuclear lamina interactions. Nature 453: 948-951.

HALLER, K., RAMBALDI, I., DANIELS, E. and FEATHERSTONE, M. (2004). Subcellular localization of multiple PREP2 isoforms is regulated by actin, tubulin and nuclear export. J Biol Chem 279: 49384-49394.

HALLER, K., RAMBALDI, I., KOVACS, E.N., DANIELS, E. and FEATHERSTONE, M. (2002). Prep2: cloning and expression of a new prep family member. Dev Dyn 225: 358-364.

IMOTO, I., SONODA, I., YUKI, Y. and INAZAWA, J. (2001). Identification and characterization of human PKNOX2, a novel homeobox-containing gene. Biochem Biophys Res Commun 287: 270-276.

IOTTI, G., LONGOBARDI, E., MASELLA, S., DARDAEI, L., DE SANTIS, F., MICALI, N. and BLASI, F. (2011). Homeodomain transcription factor and tumor suppressor Prep1 is required to maintain genomic stability. Proc Natl Acad Sci USA 108: E314-322.

IOTTI, G., MEJETTA, S., MODICA, L., PENKOV, D., PONZONI, M. and BLASI, F. (2012). Reduction of Prep1 levels affects differentiation of normal and malignant B cells and accelerates Myc driven lymphomagenesis. PLoS One 7: e48353.

KANZLEITER, T., RATH, M., PENKOV, D., PUCHKOV, D., SCHULZ, N., BLASI, F. and SCHURMANN, A. (2014). Pknox1/Prep1 regulates mitochondrial oxidative phosphorylation components in skeletal muscle. Mol Cell Biol 34: 290-298.

KAWAI, Y., ODA, A., KANAI, Y. and GOITSUKA, R. (2018). Germ cell-intrinsic requirement for the homeodomain transcription factor PKnox1/Prep1 in adult spermatogenesis. PLoS One 13: e0190702.

KHANNA, K.K. and JACKSON, S.P. (2001). DNA double-strand breaks: signaling, repair and the cancer connection. Nat Genet 27: 247-254.

LADAM, F., STANNEY, W., DONALDSON, I.J., YILDIZ, O., BOBOLA, N., and SAGERSTROM, C.G. (2018). TALE factors use two distinct functional modes to control an essential zebrafish gene expression program. Elife 7.

LAURENT, A., BIHAN, R., DESCHAMPS, S., GUERRIER, D., DUPE, V., OMILLI, F., BUREL, A. and PELLERIN, I. (2007). Identification of a new type of PBX1 partner that contains zinc finger motifs and inhibits the binding of HOXA9-PBX1 to DNA. Mech Dev 124: 364-376.

LAURENT, A., CALABRESE, M., WARNATZ, H.J., YASPO, M.L., TKACHUK, V., TORRES, M., BLASI, F. and PENKOV, D. (2015). ChIP-Seq and RNA-Seq analyses identify components of the Wnt and Fgf signaling pathways as Prep1 target genes in mouse embryonic stem cells. PLOS One 10: e0122518.

LONGOBARDI, E., IOTTI, G., DI ROSA, P., MEJETTA, S., BIANCHI, F., FERNANDEZ-DIAZ, L.C., MICALI, N., NUCIFORO, P., LENTI, E., PONZONI, M., et AL., (2010). Prep1 (pKnox1)-deficiency leads to spontaneous tumor development in mice and accelerates EmuMyc lymphomagenesis: a tumor suppressor role for
Prep1. Mol Oncol 4: 126-134.

LONGOBARDI, E., PENKOV, D., MATEOS, D., DE FLORIAN, G., TORRES, M. and BLASI, F. (2014). Biochemistry of the tale transcription factors PREP, MEIS and PBX in vertebrates. Dev Dyn 243: 59-75.

MANN, R.S. and AFFOLTER, M. (1998). Hox proteins meet more partners. Curr Opin Genet Dev 8: 423-429.

MANN, R.S. and CHAN, S.K. (1996). Extra specificity from extradenticle: the partnership between HOX and PBX/EXD homeodomain proteins. Trends Genet 12: 258-262.

MANN, R.S., LELLI, K.M. and JOSHI, R. (2009). Hox specificity unique roles for cofactors and collaborators. Curr Top Dev Biol 88: 63-101.

MARONI, G., TKACHUK, V.A., EGOROV, A., MORELLI, M.J., LUONGO, R., LEVANTINI, E., BLASI, F., MAGLI, M.C. and PENKOV, D. (2017). Prep1 prevents premature adipogenesis of mesenchymal progenitors. Sci Rep 7: 15573.

MODICA, L., IOTTI, G., D'AVOLA, A. and BLASI, F. (2014). Prep1 (pKnox1) regulates mouse embryonic HSC cycling and self-renewal affecting the Stat1-Sca1 IFNdependent pathway. PLoS One 9: e107916.

MOENS, C.B. and SELLERI, L. (2006). Hox cofactors in vertebrate development. Dev Biol 291: 193-206.

MORGAN, R., SOHAL, J., PALEJA, M. and PETTENGELL, R. (2004). Pbx genes are required in Xenopus lens development. Int J Dev Biol 48: 623-627.

NORO, B., CULI, J., MCKAY, D.J., ZHANG, W. and MANN, R.S. (2006). Distinct functions of homeodomain-containing and homeodomain-less isoforms encoded by homothorax. Genes Dev 20: 1636-1650.

ORIENTE, F., FERNANDEZ DIAZ, L.C., MIELE, C., IOVINO, S., MORI, S., DIAZ, V.M., TRONCONE, G., CASSESE, A., FORMISANO, P., BLASI, F., et AL., (2008). Prep1 deficiency induces protection from diabetes and increased insulin sensitivity through a p160-mediated mechanism. Mol Cell Biol 28: 5634-5645.

PALMIGIANO, A., SANTANIELLO, F., CERUTTI, A., PENKOV, D., PURUSHOTHAMAN, D., MAKHIJA, E., LUZI, L., DIFAGAGNA, F.D., PELICCI, P.G., SHIVASHANKAR, V., etAL., (2018). PREP1 tumor suppressor protects the late-replicating DNA by controlling its replication timing and symmetry. Sci Rep 8: 3198.

PENKOV, D., DI ROSA, P., FERNANDEZ DIAZ, L., BASSO, V., FERRETTI, E., GRASSI, F., MONDINO, A. and BLASI, F. (2005). Involvement of Prep1 in the alphabeta T-cell receptor T-lymphocytic potential of hematopoietic precursors. Mol Cell Biol 25: 10768-10781.

PENKOV, D., MATEOS SAN MARTIN, D., FERNANDEZ-DIAZ, L.C., ROSSELLO, C.A., TORROJA, C., SANCHEZ-CABO, F., WARNATZ, H.J., SULTAN, M., YASPO, M.L., GABRIELI, A., et AL., (2013). Analysis of the DNA-binding profile and function of TALE homeoproteins reveals their specialization and specific interactions with Hox genes/proteins. Cell Rep 3: 1321-1333.

PENKOV, D., PALAZZOLO, M., MONDINO, A. and BLASI, F. (2008). Cytosolic sequestration of Prep1 influences early stages of T cell development. PLOS One 3: e2424.

ROWAN, S., SIGGERS, T., LACHKE, S.A., YUE, Y., BULYK, M.L. and MAAS, R.L. (2010). Precise temporal control of the eye regulatory gene Pax6 via enhancerbinding site affinity. Genes Dev 24: 980-985.

SELLERI, L., DIMARTINO, J., VAN DEURSEN, J., BRENDOLAN, A., SANYAL, M., BOON, E., CAPELLINI, T., SMITH, K.S., RHEE, J., POPPERL, H., et AL., (2004). The TALE homeodomain protein Pbx2 is not essential for development and longterm survival. Mol Cell Biol 24: 5324-5331.

YOSHIOKA, K., ODA, A., NOTSU, C., OHTSUKA, T., KAWAI, Y., SUZUKI, S., NAKAMURA, T., MABUCHI, Y., MATSUZAKI, Y. and GOITSUKA, R. (2015). Loss of the Homeodomain Transcription Factor Prep1 Perturbs Adult Hematopoiesis in the Bone Marrow. PLoS One 10: e0136107.

ZHANG, X., FRIEDMAN, A., HEANEY, S., PURCELL, P. and MAAS, R.L. (2002). Meis homeoproteins directly regulate Pax6 during vertebrate lens morphogenesis. Genes Dev 16: 2097-2107. 


\section{Further Related Reading, published previously in the Int. J. Dev. Biol.}

Hox collinearity - a new perspective

Antony J. Durston, Hans J. Jansen, Paul In der Rieden and Michiel H.W. Hooiveld

Int. J. Dev. Biol. (2011) 55: 899-908

https://doi.org/10.1387/ijdb.113358ad

Identification of hoxb1b downstream genes: hoxb1b as a regulatory factor controlling transcriptional networks and cell movement during zebrafish gastrulation

Willem M.R. van den Akker, Antony J. Durston and Herman P. Spaink

Int. J. Dev. Biol. (2010) 54: 55-62

https://doi.org/10.1387/ijdb.082678wv

The road to the vertebral formula

Moisés Mallo, Tânia Vinagre and Marta Carapuço

Int. J. Dev. Biol. (2009) 53: 1469-1481

https://doi.org/10.1387/ijdb.072276mm

\section{Function and specificity of Hox genes}

David Foronda, Luis F. de Navas, Daniel L. Garaulet and Ernesto Sánchez-Herrero

Int. J. Dev. Biol. (2009) 53: 1409-1419

https://doi.org/10.1387/ijdb.072462df

\section{PBX proteins: much more than Hox cofactors}

Audrey Laurent, Réjane Bihan, Francis Omilli, Stéphane Deschamps and Isabelle Pellerin Int. J. Dev. Biol. (2008) 52: 9-20

https://doi.org/10.1387/ijdb.072304al
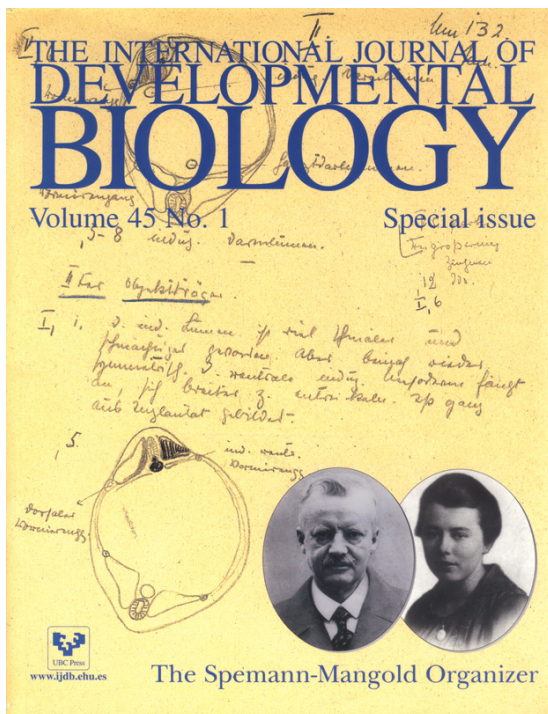

5 yr ISI Impact Factor $(2016)=2.421$

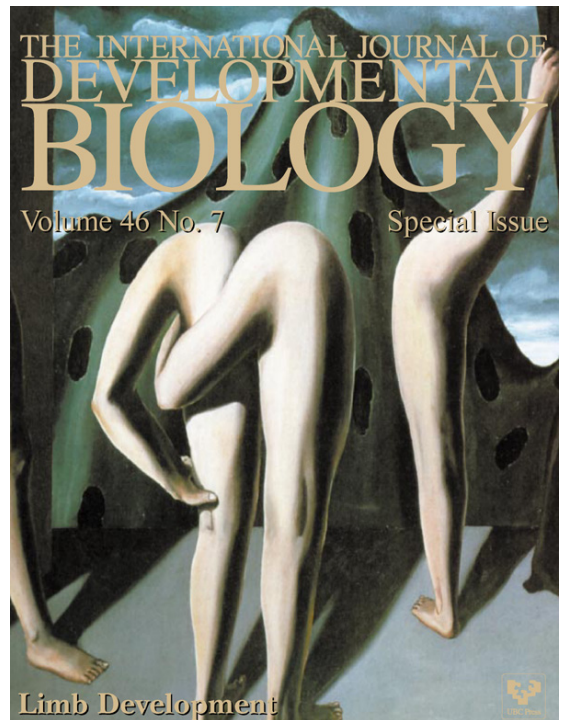

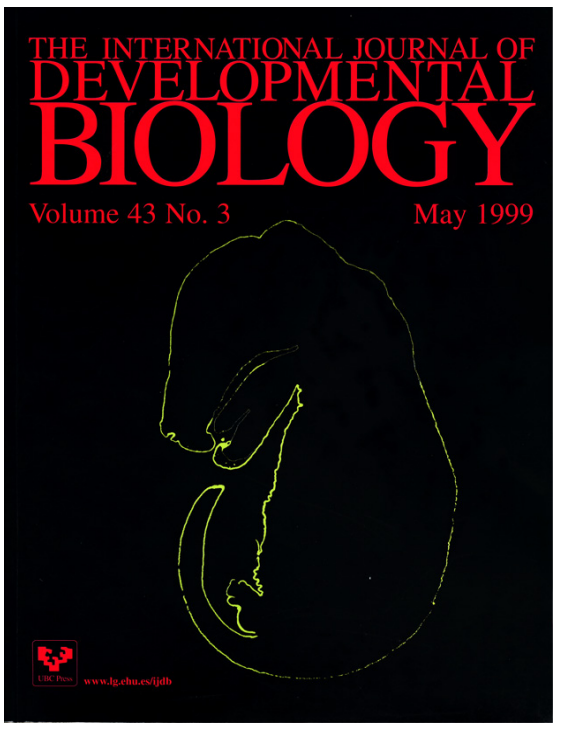

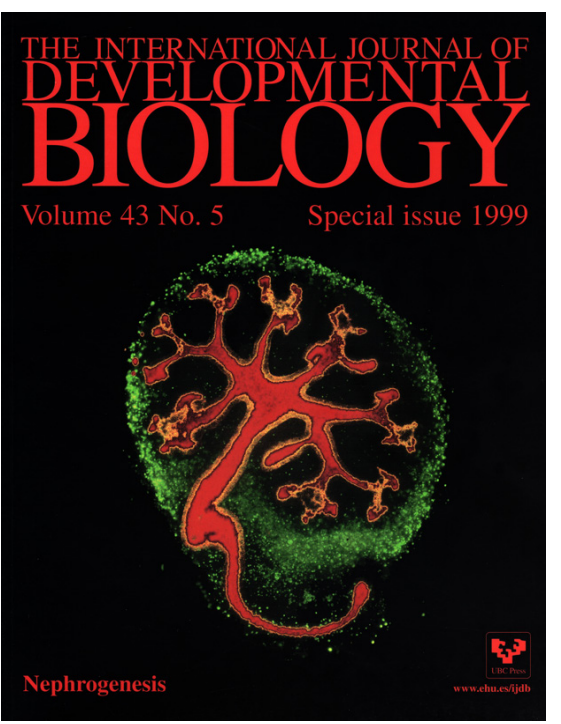

